\title{
PEMBANGUNAN MODEL E-LEARNING DI PERGURUAN TINGGI DENGAN MEMPERTIMBANGKAN FAKTOR KEBUTUHAN DINAMIS
}

\author{
Inayatulloh \\ Information Systems Department, School of Information Systems, Binus University \\ Jl. K.H. Syahdan No. 9, Palmerah, Jakarta Barat 11480 \\ inay@binus.ac.id
}

\begin{abstract}
The purpose of this research is to build a model of a dynamic e-learning that can accommodate the needs of educational institutions. The research is performed with an analysis towards the observation of the learning activities in several higher education institutions. This method is carried out as a basis for creating models of dynamic e-learning comprehensive to meet the needs of students, lecturers and all parties concerned. The result achieved is a model of e-learning that can be used by universities in building and developing elearning applications.
\end{abstract}

Keywords: dynamic e-learning, higher education institutions, students, lecturers

\begin{abstract}
ABSTRAK
Tujuan dari penelitian ini adalah membangun sebuah model e-learning yang dinamis yang dapat mengakomodasi kebutuhan lembaga-lembaga pendidikan. Metode penelitian dilakukan dengan analisis terhadap observasi proses kegiatan belajar di beberapa perguruan tinggi. Hal ini dilakukan sebagai dasar untuk menciptakan model e-learning yang dinamis komprehensif sehingga dapat memenuhi kebutuhan mahasiswa, dosen dan semua pihak terkait. Hasil yang dicapai adalah sebuah model e-learning yang dapat digunakan oleh perguruan tinggi dalam membangun dan mengembangkan aplikasi e-learning.
\end{abstract}

Kata kunci: e-learning dinamis, perguruan tinggi, mahasiswa, dosen 


\section{PENDAHULUAN}

Perkembangan teknologi informasi berdampak pada semua aspek kehidupan dari aspek yang sederhana sampai hal besar yang mempengaruhi hajat hidup orang banyak. Salah satu bidang yang sangat dipengaruhi oleh perkembangan teknolgi informasi adalah bidang pendidikan. Di beberapa institusi pendidikan semua kegaitan sudah sangat bergantung pada teknologi informasi mulai dari pendaftaran, proses belajar mengajar, sistem pembayaran, penilaian dan lain sebaginya. Meskipun demikian masih sangat banyak lembaga pendidikan yang menggunakan teknologi informasi hanya untuk mendukung proses belajar mengajar atau biasa disebut $e$-learning system. E-learning merupakan sebuah metode pembelajaran menggunakan teknolgi informasi sebagai alat bantu atau pendukung proses belajar mengajar. Dalam konteks penerapannya e-learning tidak hanya digunakan di institusi pendidikan tapi juga di beberapa perusahaan sebagai media pelatihan atau training, upgrading karyawan dan lain sebagainya.

Pembangunan e-learning di beberapa lembaga pendidikan pada umumya memiliki kesamaan dan perbedaan dalam beberapa aspek karena penggunaan sistem atau prosedur yang juga berbeda. Aspek yang hampir sama pada setiap pembangunan e-learning pada beberapa lembaga pendidikan di antaranya: (1) fitur upload download materi untuk dosen dan mahasiswa; (2) fitur online learning yang meliputi materi kuliah, jadwal kuliah, jumlah pertemuan, metode pembelajaran dan lain sebagainya; (3) fitur kehadiran mahasiswa dan dosen; (4) fitur informasi hasil belajar dan lain sebagainya. Adapun perbedaan perbedaan aspek dari beberapa pembangunan e-learning di antaranya: (1) fitur online exam; (2) penggabungan informasi administrasi pembayaran dengan kegiatan belajar mengajar; (3) integrasi data dosen, mahasiswa dan semua kegiatan belajar mengajar, dan lain sebagainya. Dengan mempertimbangkan faktor-faktor tersebut, diperlukan sebuah model $e$ learning yang dapat mengakomodasi kebutuhan yang berbeda dengan menggunakan model yang sama.

\section{Model}

Turban (2003) mendefinisikan model sebagai a simplified representation or abstraction of reality which can be manipulated and the effects of such testing analyzed, yang artinya suatu penyajian yang disederhanakan atau penyederhanan (abstraction) dari suatu realitas yang dapat dimanipulasi dan mempunyai dampak seperti analisis dan pengujian.

Penyederhanaan (simplification) digunakan apabila realitas yang dihadapi sangat besar dan kompleks untuk digunakan secara langsung dan karena kompleksitasnya itu kenyataannya menjadi tidak relevan untuk sebuah permasalahan khusus. Penyajian (representation) dengan model dapat dilakukan ke dalam beberapa tingkatan abstraksi, yang umumnya diklasifikasikan menjadi empat yaitu: iconic model, analog model, mathematical model dan mental model.

Model iconic yaitu yang berupa fisik, ada skalanya, biasanya tiga dimensi; Model analog adalah model fisik tetapi tidak digambar seperti benda aslinya, dapat berupa chart atau cetakbiru; Model mathematical dinyatakan secara kuantitatif, pengolahannya dengan angka, meskipun dewasa ini telah dapat diolah secara visual; Model mental yaitu menjelaskan bagaimana orang memikir sesuatu, kepercayaan, asumsi, relasi dan lainnya.

\section{Sistem Informasi}

Sistem Informasi (SI) merupakan komponen-komponen yang saling berkaitan, yang saling bekerjasama untuk mengumpulkan, memproses, menyimpan, dan menyebarkan informasi untuk mendukung pengambilan keputusan, koordinasi, kontrol, analisis, dan visualisasi dalam suatu 
organisasi (Laudon dan Laudon, 2004, p.8). SI juga dapat diartikan sebagai mengumpulkan, memproses, menganalisis, dan menyebarkan informasi untuk tujuan yang spesifik (Turban et al., 2006: 20).

Apabila dilihat dari definisi tersebut, akan terlihat bahwa SI ini mempunyai cakupan yang sangat luas baik dari segi teknis maupun penerapannya dalam suatu organisasi. Salah satu pendekatan yang dapat digunakan untuk lebih memahami fungsi SI dalam konteks organisasi yang lebih luas adalah knowledge management (KM) (Petrides, 2004, p.3).

KM merupakan salah satu pendekatan yang berpusat pada manusia, serta dapat digunakan untuk melihat hubungan yang saling berkaitan dan berkelanjutan antara manusia, proses, dan sistem teknologi (Petrides, 2004, p.3). Pemahaman lain dari KM adalah sebagai proses menangkap atau menciptakan pengetahuan, menyimpannya, memperbaruinya secara berkala, menginterpretasikannya, dan menggunakannya kapanpun dibutuhkan (Turban et al., 2006, p.19).

Pendekatan KM adalah integrasi antara manusia, proses, dan teknologi yang terlibat dalam merancang, menangkap, dan mengimplementasikan infrastruktur intelektual dari sebuah organisasi. KM tidak hanya menekankan pada desain dan implementasi SI, tapi juga meliputi perubahan penting dalam sikap manajemen, perilaku organisasional, dan kebijakan. Hal inilah yang memungkinkan orang-orang dalam organisasi untuk mengembangkan kemampuan untuk mengumpulkan informasi dan berbagi informasi yang mereka ketahui, sehingga hal ini akan mengarah pada tindakan yang meningkatkan pelayanan dan kinerja (Petrides, 2004, p.3).

Banyak aplikasi dari pendekatan KM ini yang telah diterapkan oleh perusahaan maupun oleh organisasi lain terutama institusi pendidikan. Contoh nyata dari penerapan KM adalah penerapan $e$ learning. Dalam menerapkan e-learning, definisi KM ini akan muncul dengan sendirinya karenakan tujuan dari e-learning ini sama dengan konsep KM, yaitu mengumpulkan dan berbagi ilmu pengetahuan untuk mencapai keunggulan kompetitif.

\section{E-learning}

E-learning, e-education, atau online learning mengacu pada cara orang berkomunikasi dan belajar secara elektronik yang akhir-akhir ini muncul sebagai satu-satunya kunci untuk mencapai keunggulan kompetitif di dalam lingkungan yang penuh dengan informasi (Roffe, 2002, p.40). Elearning juga dapat diartikan sebagai penciptaan dan pendistribusian pengetahuan melalui penyampaian informasi, komunikasi, pendidikan, dan pelatihan secara online (Wild et al., 2002, p.371). Definisi lain dari e-learning adalah penyampaian pelatihan dan pendidikan melalui interaksi jaringan dan dari kumpulan pengetahuan dan distribusi teknologi yang lain (Fry, 2001, p.234).

Makna huruf ' $e$ ' pada $e$-learning bukan hanya sekedar mengartikan kata electronic, kata $e$ di sini mengacu pada pemahaman yang lebih luas lagi. ' $E$ ' di sini bisa diartikan sebagai perbaikan (enhancement), baik perbaikan bagi para pelajar maupun perbaikan pembelajaran itu sendiri, pengalaman dalam bereksplorasi (experience), kemudahan penggunaan (ease of use), pemberdayaan (empowerment) pelajar untuk mengontrol jadwal pembelajaran, dan pelaksanaan (execution) dari program pembelajaran (Roffe, 2002, p.41).

E-learning membawa proses perubahan dalam proses belajar mengajar. Proses belajar mengajar yang tadinya lebih bersifat teacher-centred approach (pendekatan pembelajaran yang berfokus pada guru) menjadi student-centred approach (pendekatan pembelajaran yang berfokus pada murid). Dalam teacher-centred approach, guru merupakan gerbang informasi yang menyebarkan pengetahuan kepada para muridnya sehingga murid lebih bersikap pasif dengan menerima segala apa yang diberikan oleh guru atau pengajarnya. Di sini murid tidak berkesempatan untuk mendapatkan informasi yang benar dan belajar untuk menggunakan kemampuan berfikir dalam level yang lebih 
tinggi, seperti menganalisis, menyaring, serta mengevaluasi untuk penyebaran informasi kepada orang lain. Hal ini akan berkebalikan dengan student-centred approach. Pendekatan ini percaya bahwa murid adalah peserta aktif dan dapat mengembangkan pengetahuan mereka sendiri dengan cara berinteraksi dengan informasi yang ada. Pandangan ini menempatkan murid sebagai pusat dari proses pembelajaran dan meyakini bahwa guru adalah penasihat, penunjuk arah, fasilitator atau pemandu yang membantu murid untuk mengakses, mengatur, membangun, dan mentransfer informasi untuk memecahkan suatu masalah. Jadi, dalam pendekatan ini murid akan mendapatkan keuntungan tidak hanya dalam konteks yang sedang dipelajari, akan tetapi juga mendapatkan keuntungan dari proses pembelajaran, misalnya saja bagaimana cara untuk belajar melalui penemuan, penyelidikan, dan pemecahan masalah (Bose, 2003, p.194).

Dalam e-learning yang menjadi pusat pembelajaran serta yang memegang peranan terbesar adalah murid atau pelajar, sehingga yang pertama kali perlu diperhatikan dalam proses pengembangan pembelajaran menggunakan e-learning adalah pelajar itu sendiri. Dalam tahap awal proses e-learning, biasanya pengembangan sarana teknis serta berbagai media pendukunglah yang didahulukan, baru kemudian mencari siapa yang mau serta mampu untuk menggunakannya. Padahal seharusnya hal yang paling utama untuk diperhatikan adalah dari segi pelajar itu sendiri. Hal ini mencakup kebutuhan pelajar, riwayat pembelajaran pelajar, tujuan pelajar dalam pembelajaran, isi pembelajaran yang menjadi minat pelajar, serta pertanyaan apakah e-learning lebih memotivasi pelajar daripada proses pembelajaran tradisional. Kesuksesan e-learning terutama dipengaruhi oleh sikap pelajar itu sendiri terhadap situasi pembelajaran (Littig, 2006, p.89).

Roffe (2002, p.42) menyatakan bahwa dalam e-learning dibutuhkan adanya penjaminan mutu dari pembelajaran jarak jauh, serta adanya evaluasi dalam e-learning. Maksud dari penjaminan mutu di sini adalah untuk dapat menunjukkan bahwa program yang ditawarkan oleh pembelajaran jarak jauh adalah sama dengan metode pembelajaran di dalam kelas. Sedangkan proses evaluasi di sini bukanlah untuk mengatakan bahwa seseorang telah melakukan kesalahan atau akan mengalami kegagalan, tetapi proses evaluasi di sini merupakan proses untuk menunjukkan apa yang perlu untuk ditingkatkan dan langkah apa yang sebaiknya dilakukan untuk ke depannya nanti.

Kadang sering muncul beberapa kesalahpahaman dalam pelaksanaan e-learning. Beberapa orang berpendapat bahwa e-learning berarti menaruh semua pengetahuan dalam komputer. Pelajar dapat belajar di manapun dan kapanpun mereka suka, hanya mempelajari apa yang mereka butuhkan serta dapat belajar dengan cara yang optimal. Kadang kita lupa bahwa sebenarnya pembelajaran adalah suatu proses sosial. Sekalipun pembelajaran dilakukan dalam kelas, proses pembelajaran ini justru terjadi di luar kelas antar pelajar itu sendiri. Oleh karena itulah, kadang pembelajaran dapat berlangsung dengan baik apabila pembelajaran dengan mediasi komputer digabungkan dengan kelas virtual, kelompok belajar, tugas kelompok, kegiatan off-line, serta bimbingan online dari pengajarnya (Bose, 2003, p.194).

Wild et al. (2002, p.376) menyatakan bahwa dalam pelaksanaan e-learning bukan berarti konsep pembelajaran tradisional benar-benar ditinggalkan. Dalam pelaksanaan e-learning, karakteristik pembelajaran tradisional yang sesuai dapat dipakai untuk melengkapi karakteristik dari online learning. Beberapa karakteristik tersebut dapat dilihat dari tabel 1. Dengan menggabungkan kedua konsep tersebut diharapkan akan tercipta hasil pembelajaran yang lebih optimal. Tabel $1 \mathrm{di}$ bawah ini memuat perbedaan penyajian online learning dengan pembelajaran tradisional.

Tabel 1

Penyajian Pengetahuan untuk E-learning (Wild et al., 2002)

Karakteristik Pembelajaran Tradisional

(1) Mengikut sertakan pengajar sepenuhnya;

(2) Mendorong pengembangan kemampuan cognitive;
Karakteristik Online Learning

(1) E-learning harus interaktif;

(2) E-learning harus membuat sarana untuk mengulang 


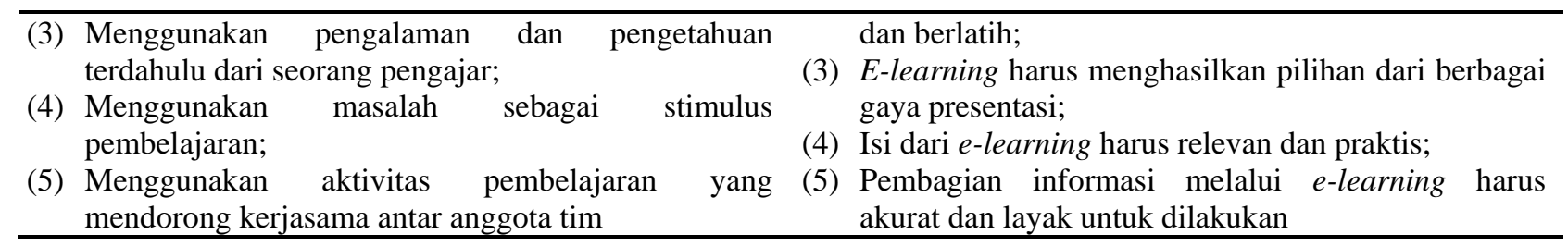

Agar menjadi sebuah sarana pengetahuan yang efektif, perlu dikembangkan suatu kerangka pengembangan e-learning. Kerangka tersebut meliputi kesiapan organisasi dalam menerapkan elearning (meliputi infrastruktur, budaya organisasi, sikap karyawan atau pelajar. Serta kebutuhan pengetahuan, perancangan isi e-learning yang layak untuk digunakan, perancangan penyajian $e$ learning yang layak, serta pertimbangan dalam implementasi e-learning (Wild et al., 2002, p.374).

Dalam perkembangannya, online learning dapat dibedakan menjadi dua model dasar, yaitu campus-based model serta distance based model. Campus-based model memandang media online sebagai pelengkap untuk model penyampaian tradisional, sedangkan distance-based model memandang online learning sebagai pengganti untuk bentuk penyampaian tradisional. Distance-based model dapat berbentuk campuran (media campuran, termasuk cetakan, CD, DVD dan yang lainnya, atau mengkombinasikan semua itu dengan pertemuan langsung) atau dapat juga berbentuk pure play (eksklusif secara online, dengan semua bahan pembelajaran melalui internet) (Ennew dan FernandezYoung, 2006, p.148).

Online learning yang digunakan sebagai pengganti penyampaian tradisional memerlukan pertimbangan yang lebih matang daripada online learning yang digunakan hanya sekedar sebagai pelengkap penyampaian tradisional. Keterbatasan pemahaman serta pengetahuan mengenai apa yang sebenarnya diinginkan oleh pasar (pelajar atau karyawan) serta penerapan tujuan yang kurang jelas akan menimbulkan posisi organisasi yang tidak jelas dalam pasar itu sendiri. Selain itu menentukan tujuan untuk jangka panjang juga dapat mendukung keberhasilan dari online learning itu sendiri (Ennew dan Fernandez-Young, 2006, p.155). Pelaksanaan e-learning membutuhkan umpan balik dari para pelakunya. Selain itu, pengajar harus bekerja lebih keras dalam membangun komunitas online, serta lebih melibatkan para pelajar dalam perancangan pembelajaran (Slotte dan Herbert, 2006, p.30). Sehingga dalam prakteknya, perlu pertimbangan dari semua pihak yang terkait agar pelaksanaan serta hasil dari e-learning dapat optimal serta sesuai dengan pencapaian yang diinginkan.

\section{METODE}

Metode penelitian dilakukan dengan analisis terhadap observasi proses kegiatan belajar di beberapa perguruan tinggi. Hal ini dilakukan sebagai dasar untuk menciptakan model e-learning yang dinamis komprehensif sehingga dapat memenuhi kebutuhan mahasiswa, dosen dan semua pihak terkait.

\section{HASIL DAN PEMBAHASAN}

Proses belajar mengajar di perguruan tinggi yang masih konvesional secara umum adalah sebagai berikut: kegiatan belajar mengajar atau pelatihan dimana seorang instruktur menjelaskan materi dari satu sumber kemudian audience atau mahasiswa mendengarkan dan menyimak materi yang disampaikan. Instruktur telah mempersiapkan materi atau bahan ajar kemudian menampilkannya pada layar dan menjelaskan kepada audience. Kegiatan lain seperti diskusi atau tanya jawab juga 
dilakukan pada tempat dan waktu yang sama demikian juga latihan dan pengumpulan tugas dilakukan pada waktu dan tempat yang sama. Kegiatan belajar mengajar konvensional ini dapat dijelaskan seperti Gambar 1 berikut:

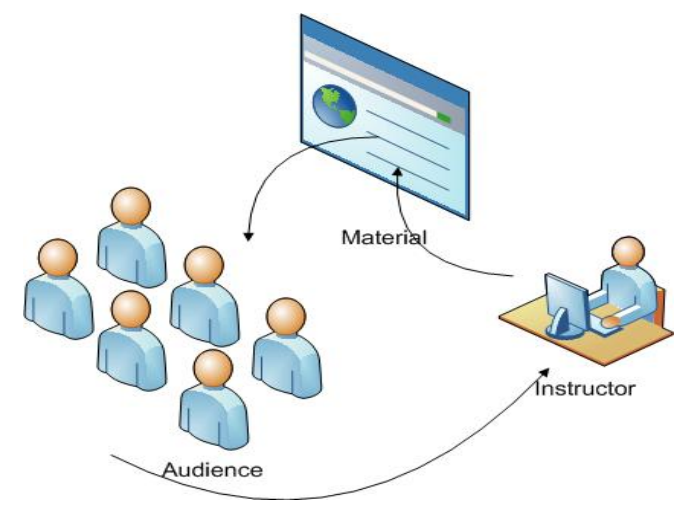

Gambar 1. Proses belajar mengajar konvesional di perguruan tinggi.

E-learning system yang dibangun pada AMIK ASM LAKSI31 berbasis web atau internet menggabungkan aktor yang terlibat pada sistem yakni administrator, dosen dan mahasiswa. Seorang dosen dapat melakkukan upload materi dan tugas dengan sebelumnya melakukan login. Registrasi dosen dan mahasiswa dilakukan oleh administrator agar dosen dan mahasiswa dapat melakukan unduh (download) dan unggah (upload) materi.

Mahasiswa dapat melakukan unduh materi dan unduh jawaban berdasarkan materi yang telah diunggah oleh dosen maupun adminsitrator. Proses dimulai dari administrator yang memasukkan semua aktor baik dosen maupun mahasiswa kedalam database sistem. Kemudian dosen melakukan login untuk melakukan unggah materi. Pada pelaksanaan perkuliahan dosen dan mahasiswa dapat menggunakan materi yang ada pada e-learning system yang telah diunggah oleh dosen.

Jika hendak memberikan tugas, dosen dapat menggunakan fasilitas unggah tugas yang akan dilihat oleh mahasiswa yang bersangkutan. Mahasiswa dapat mengunggah jawaban dari tugas yang telah diberikan oleh dosen. Gambar 2 berikut merupakan e-learning system yang dibangun pada AMIK LAKSI 31. Kebutuhan perangkat keras dan jaringan yang dimiliki oleh lembaga telah memadai sehingga implementasi e-learning system ini dapat dilakukan. Rencana implementasi dilakukan secara bertahap dengan melakukan beberapa simulasi dari modul yang ada di e-learning system. 


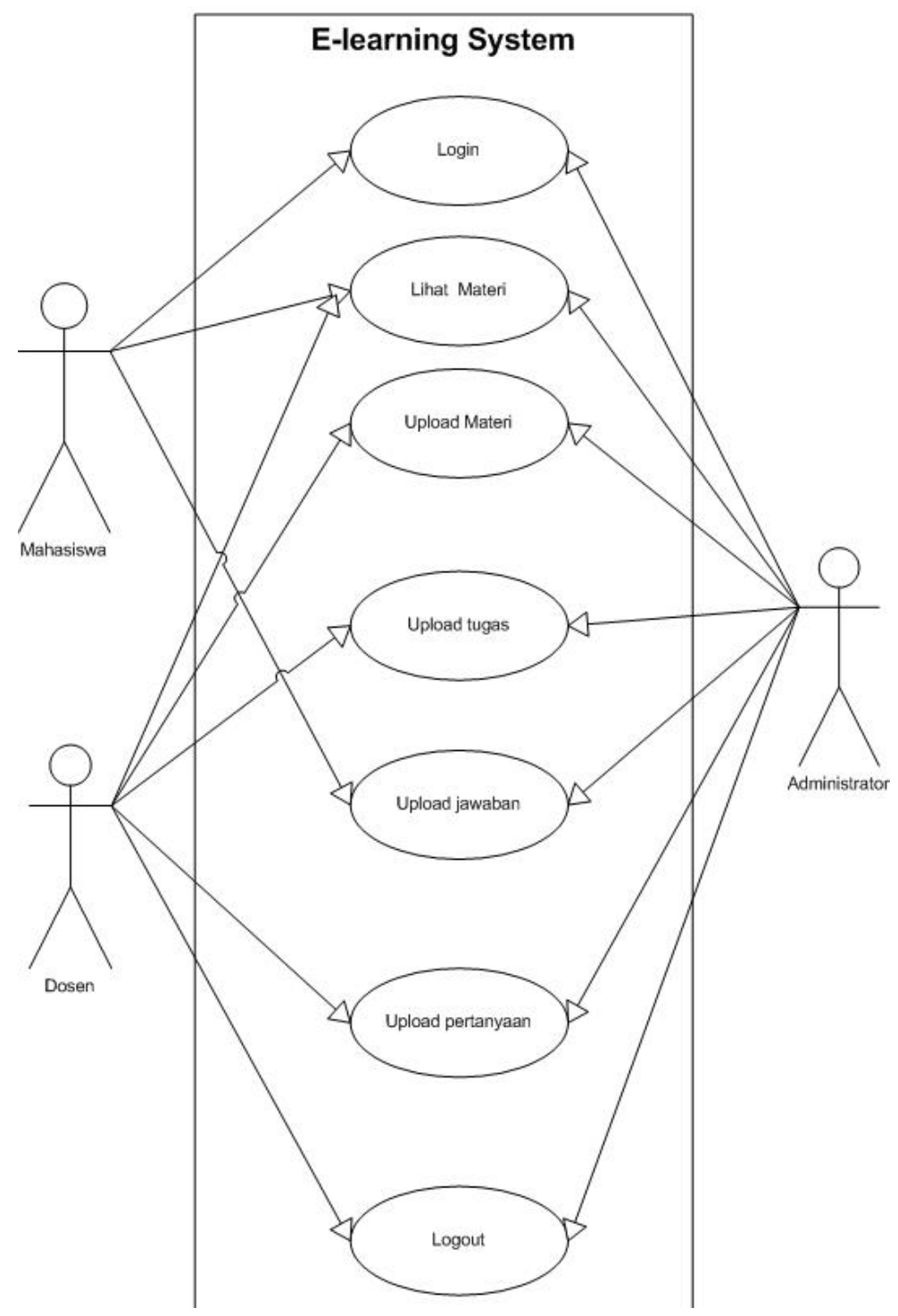

Gambar 1. E-learning system yang dibangun.

\section{PENUTUP}

Berdasarkan hasil bahasan aplikasi front office dan back office dari seluruh user yaitu mahasiswa, dosen dan admin pada aplikasi ini terintegrasi pada satu sistem e-learning. Hal ini akan sangat membantu dosen dan mahasiswa dalam melakukan kegiatan belajar mengajar secara online dan memudahkan admin dalam mengelola data dan informasi mengenai kegiatan belajar mengajar.

Sistem ini membantu lembaga pendidikan untuk dapat meningkatkan efektifitas dan efisiensi proses pembelajaran secara online dimana peningkatan efisiensi dan efektifitas tersebut akan meningkatkan kinerja perguruan tinggi atau lembaga tersebut secara keseluruhan 


\section{DAFTAR PUSTAKA}

Bose, Kabita. (2003). An E-learning Experience: A Written Analysis based on My Experience in an Elearning Pilot Project. Campus-Wide Information Systems, 20 (5), 193-199.

Ennew, Christine T. \& Fernandez-Young, Anita. (2006). Weapons of Mass Construction? The Rethoric and Reality of Online Learning. Marketing Intelligence and Planning, 24 (2), 148157.

Fry, Kate. (2001). Part Two E-learning, E-learning Markets and Providers: Some Issues and Prospects. Education + Training, 43 (4/5), 233-239.

Laudon, Kenneth C. \& Laudon, Jane P. (2004). Management Information Systems: Managing The Digital Firm. New Jersey: Prentice Hall.

Littig, Peter. (2006). New-Media Supported Learning Today and Tomorrow: Recommendations for The Next Generation of Education and Training Concepts Supported by New Learning Media. Industrial and Commercial Training, 38 (2), 86-92.

Petrides, Lisa A. (2004). Knowledge Management, Information Systems, and Organizations. Educause. 2004 (20): 1-12.

Roffe, Ian. (2002). E-learning: Engagement, Enhancement, and Execution. Quality Assurance in Education, 10 (1): 40-50.

Slotte, Virpi \& Herbert, Anne. (2006). Online Learning vs Print Learning, Which One Provides The Better Result? Development and Learning in Organizations, 20 (6), 29-31.

Turban, E., Leidner, D., McLean, E., \& Wetherbe, J. (2006). Information Technology for Management: Transforming Organizations in the Digital Economy. Asia: Wiley.

Turban, E., Viehland, D. \& Dan Lee, J. (2006). Electronic Commerce: A Managerial Perspective. New Jersey: Pearson Prentice Hall. 